Canadian

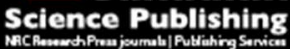

Canadian Geotechnical Journal Revue canadienne de géotechnique

\title{
Compression and shear strength characteristics of compacted loess at high suctions
}

\begin{tabular}{|r|l|}
\hline Journal: & Canadian Geotechnical Journal \\
\hline Manuscript ID & cgj-2016-0347.R2 \\
\hline Date Submitted by the Author: & 17-Nov-2016 \\
\hline Complete List of Authors: & $\begin{array}{l}\text { Ng, C.W.W.; Hong Kong University of Science and Technology, Department } \\
\text { of Civil and Environmental Engineering } \\
\text { Sadeghi, Hamed; Hong Kong University of Science and Technology, } \\
\text { Department of Civil and Environmental Engineering; Sharif University of } \\
\text { Technology, Department of Civil Engineering } \\
\text { Jafarzadeh, Fardin; Sharif University of Technology, Department of Civil } \\
\text { Engineering }\end{array}$ \\
\hline Keyword: & direct shear tests, high suction range, dilatancy, collapse, shear strength \\
\hline & \multicolumn{2}{|c}{} \\
\hline
\end{tabular}




\section{Title of paper:}

Compression and shear strength characteristics of compacted loess at high suctions

\section{Author's affiliation and address:}

Name: Charles Wang Wai Ng

Affiliation: Chair Professor

Address: Department of Civil and Environmental Engineering, Hong Kong University of Science and Technology, Clear Water Bay, Kowloon, Hong Kong

E-mail: cecwwng@ust.hk

Name: Hamed Sadeghi* (Corresponding author)

Affiliation: $\mathrm{PhD}$

Address: Department of Civil and Environmental Engineering, Hong Kong University of Science and Technology, Clear Water Bay, Kowloon, Hong Kong

Address: Department of Civil Engineering, Sharif University of Technology, Tehran, Iran

E-mail: hsadeghi@connect.ust.hk

Name: Fardin Jafarzadeh

Affiliation: Associate professor

Address: Department of Civil Engineering, Sharif University of Technology, Tehran, Iran

E-mail: fardin@sharif.edu 


\title{
Compression and shear strength characteristics of compacted loess at high suctions
}

Charles Wang Wai Ng, Hamed Sadeghi, and Fardin Jafarzadeh

\begin{abstract}
Compression and shear behavior of a loosely compacted loess is investigated via two series of saturated and unsaturated direct shear tests. Vapor transfer mechanism is used to modify a shear box device for control of suction at high range. In spite of significant volumetric strain upon wetting (up to $14 \%$ ), suctioninduced volumetric shrinkage is less than $2 \%$ for all suction levels considered because of the as-compacted moisture content at dry side of the optimum value. During shearing, all unsaturated tests dried to high suctions indicate strain softening mode of failure associated with noticeable dilation. There is a continuous increase in peak strength with suction but at a reduced rate, which cannot be captured by the improved Bishop's effective stress model since it underestimates the contribution of high suctions by approaching zero degree of saturation. Unsaturated tests at high suctions also show an increased rate of dilation with suction for both values of net stress, which cannot be predicted well by the classical stressdilatancy models. It is shown that for suction values beyond 8 $\mathrm{MPa}$, dilation angle increases by $2^{\circ}$ and $6^{\circ}$ per $100 \mathrm{MPa}$
\end{abstract}


increase of suction under net stress of 50 and $200 \mathrm{kPa}$, respectively.

key words: direct shear tests; high suction range; dilatancy; shear strength; collapse

\section{Introduction}

Understanding of shear strength and shear behavior associated with dilatancy of soils subjected to different stress paths and having different states comprises a notable body of research in geotechnical related fields. Compared to the studies on shear characteristics of saturated geo-materials, far less research has been conducted on unsaturated soils. Alonso et al. (2007) studied dilatancy of compacted coarse gravels of hard limestone desiccated to high suctions. Results clarified that conventional frameworks of dilatancy as pure functions of the current stress ratio and the limiting stress ratio cannot satisfactorily describe shear behavior. Ng and Chiu (2003) also reported that dilatancy of loose unsaturated weathered soils is affected by stress path, suction, and state. These observations became the basis for development of a state-dependent elasto plastic model (Chiu and Ng 2003). Hossain and Yin (2010) observed an increase in dilatancy of compacted decomposed granite due to a rise in suction for low net normal stress levels in spite of zero rate of dilation for saturated tests. Similar trends 
were also reported for compacted soil-cement interface (Hossain and Yin 2015). Dilative and contractive behavior was observed by Melinda et al. (2004) for compacted sandy lean clay compressed to low and high net stress, respectively. Experimental observations of Goh et al. (2010) highlighted the significance of hysteresis in addition to suction on shear strength and shear behavior, which is also valid for cyclic wetting and drying tests (Goh et al. 2014). Compacted sandkaolin specimens along wetting path were stiffer and had lower shear strength, and dilated more during shearing compared to the specimens on drying curve.

Regarding undisturbed soils with more emphasis on loess, Munõz-castelblanco et al. (2012) observed progressive development of compressive strain after yielding in constantwater unsaturated shearing tests. Similar trends were reported by Akbari Garakani et al. (2015) for undisturbed loess of Iran under low suction or high mean net stress. However, dilative behavior was characterized for higher suction of $300 \mathrm{kPa}$. Zhan and $\mathrm{Ng}$ (2006) reported increase of dilatancy with suction for compacted and natural expansive clay. The cementation in natural specimens resulted in a higher rate of dilation as well as a higher peak strength for all suction levels up to $200 \mathrm{kPa}$. Wang and Leung (2008) also reported the increase of dilatancy at peak stress ratio due to artificial cementation. A significant increase in the initial stiffness of compacted silt was observed 
by Vassallo et al. (2007) as suction increased beyond the past maximum value. Their results confirmed the dependency of stiffness on both stress state variables and stress history ( $\mathrm{Ng}$ and $\mathrm{Xu} 2012$ ). Effects of compaction conditions on the initial stiffness were studied by Heitor et al. (2013) through bender element tests on a compacted silty sand. They showed that the stiffness was affected by compaction energy on dry of the optimum water content and also by the soil structure on the wet of the optimum. Changes in the soil macrostructure were also demonstrated by CT-scan images.

Experimental results on shear strength characteristics of geomaterials at high suction range are very limited. Results of unconfined compression tests on a compacted silty soil by Nishimura and Fredlund (2001) indicated that shear strength remains relatively constant beyond the residual suction. Alsherif and McCartney (2014) evaluated the principle of effective stress proposed by $\mathrm{Lu}$ and Likos (2006) for an unsaturated compacted silt at low degree of saturation. Suction stress was found to be over-predicted if the water retention curve is obtained from water retention data at low suction range. Predictions can be improved, however, if small adjustments are applied to the water retention curve. Furthermore, Oh and $\mathrm{Lu}$ (2014) showed that a unique water retention curve can be defined if the effective degree of saturation is used. Results of drained triaxial compression tests 
on a compacted silt reported by Alsherif and McCartney (2015) revealed the brittle type failure mechanism at high suctions. On the contrary, strain hardening mode of failure was observed under saturated conditions, indicating the possible induced dilatancy by suction. Pineda et al. (2014) noticed that cyclic change of relative humidity $(\mathrm{RH})$ has significant influence on reduction of saturated cohesion and friction angle but at different rates. It also hinders brittleness and dilation angle. Merchán et al. (2011) reported noticeable increase in residual friction angle of Boom clay due to the increase of suction from zero to $140 \mathrm{MPa}$. The enhancement of dilatancy with suction was attributed to the induced aggregated structure at high suctions.

Suction contributes not only to the dilatancy and strength but also to the volume changes. In most of research conducted so far, there is no distinction between suction-induced volumetric shrinkage and suction-induced dilatancy. This is because changes in suction and void ratio are usually coupled. However, a soil compacted dry of optimum and directly dried to high suction levels beyond the residual state can provide a suitable material to highlight the pure influence of suction on dilatancy. Therefore, the main objective of this paper is to study the significance of suction on shear strength and shear behavior of compacted loess. In addition, results of wetting-induced 
collapse, suction-induced shrinkage, and compressibility at high suction range are presented and discussed.

\section{Experimental procedure}

\section{Soil type and sample preparation}

Block loess samples were retrieved from a pit in Xi'an, Shaanxi province of China. Soil samples were taken at four different depths from $1.5 \mathrm{~m}$ to $7.5 \mathrm{~m}$ with $2 \mathrm{~m}$ intervals. Based on the results of index tests, test material has a specific gravity of 2.69. Plastic limit and liquid limit were also obtained as $19 \%$ and $36 \%$, respectively. Sand, silt, and clay contents of loess are $0.1 \%, 71.9 \%$, and $28.0 \%$, respectively. The soil is therefore classified as a clay of low plasticity or CL according to the USCS (ASTM D 2487). Based on measurements conducted on 8 samples from different depths, the average unit dry weight and water content were determined as $12.57 \mathrm{kN} / \mathrm{m}^{3}$ and $12.0 \%$, respectively. Fig. 1 shows results of compaction test on loess with standard Proctor effort. Results clarify the state of intact loess on dry side of optimum with a relative compaction of $76 \%$.

Recompacted specimens were prepared following the same dry density and water content as those of in-situ soil samples. Although the re-compaction procedure is intended to mimic the void ratio and water content, the microstructure possessed by intact loess cannot be reproduced in the recompacted 
specimens. $500 \mathrm{~g}$ of oven dried sieved ( $2 \mathrm{~mm}$-aperture) intact soil was mixed with target water content until a uniform mixture was obtained. The wet mixture was sieved through 2 mm-aperture sieve and the remaining part was mixed again. This procedure was repeated until no more soil remained on the sieve. The wet mixture was sealed in a plastic bag and transferred to an ice chest for moisture equalization overnight. Test specimens were prepared in three layers following the static compaction procedure with a displacement rate of 1 $\mathrm{mm} / \mathrm{min}$. A three-piece split mold facilitating the extrusion of specimen was used. The width, length, and height of the mold are $50.8,50.8$, and $21.4 \mathrm{~mm}$, respectively. The specimen dimensions were measured afterwards by using a caliper readable to $0.01 \mathrm{~mm}$. Specimens were eventually weighed by a balance with the resolution of $0.01 \mathrm{~g}$ and water content measurements were taken for the rest of soil used for preparation.

\section{Test apparatus and measuring devices}

A conventional direct shear box was modified to control suction at high magnitudes during a test (Fig. 2). The modifications were applied to the device previously developed by Zhan (2003) for unsaturated testing at low range of suction up to $500 \mathrm{kPa}$. The upper limit of $500 \mathrm{kPa}$ is controlled by the 5-bar HAE ceramic disk implemented into the base pedestal. In other words, the original version worked based on the principle 
of the axis-translation technique and was utilized successfully in previous research (e.g. Ng and Zhou 2005; Zhan and Ng 2006). In the new design ( $\mathrm{Ng}, 2014)$, however, range of suction is extended to high magnitudes in the order of tens of MPa by incorporating vapor equilibrium technique (Blatz et al. 2008). Therefore, suction can be controlled through vapour transfer mechanism inside the isolated stainless steel chamber surrounding the whole shear box.

In order to provide an isolated environment having a certain RH, 8 Plexiglas cylinders were attached to the internal wall of shear box chamber. The cylinders serve as containers for salt solutions. A total volume of $520 \mathrm{ml}$ is provided by all containers, which is considered enough for providing an environment with a stable RH. Moreover, the whole shear box apparatus was put inside a temperature controlled room with daily temperature fluctuation of $\pm 0.5{ }^{\circ} \mathrm{C}$. The error related to suction imposed corresponding to temperature fluctuations was estimated to be 0.01 and $0.43 \mathrm{MPa}$ for the minimum and maximum suction considered (i.e., 7 and $231 \mathrm{MPa}$ ), respectively. The induced error in suction by temperature fluctuations is less than $0.2 \%$ in all cases. Nevertheless, the thermal effects on water retention and shear strength characteristics cannot be neglected if temperature changes are too large to be ignored (Tang and Cui 2005). Therefore, suction can be evaluated according to Kelvin law provided that $\mathrm{RH}$ and 
temperature are recorded regularly. Besides, four conventional desiccators were used as ancillary devices to speed up suction equalization of test specimens before being transferred to the shear box chamber. Four types of saturated salt solutions were used to generate target $\mathrm{RH}$ and hence suction. Potassium nitrate, Sodium chloride, Magnesium chloride hexahydrate, and Lithium chloride were used to produce nominal suction potential of $8 \mathrm{MPa}, 40 \mathrm{MPa}, 125 \mathrm{MPa}$, and $230 \mathrm{MPa}$, respectively.

The direct shear box was equipped with two pairs of LVDTs for monitoring vertical and horizontal displacements together with a load cell for measuring shear forces. Three sensors were calibrated for their working range accordingly. Vertical stress was applied by adjustable dead load. The apparatus was also calibrated for compliance errors come from the application of vertical load for the entire range of stress considered in this study. In addition to the conventional sensors, a temperature/humidity data logger was used to monitor both relative humidity and temperature during the whole test. The recorded data was used afterwards for calculation of total suction. The $\mathrm{T} / \mathrm{H}$ sensor was also calibrated by using saturated salt solutions with known potential of $\mathrm{RH} /$ suction. In order to accelerate homogenization of $\mathrm{RH}$ throughout the chamber, an agitation fan was incorporated into the isolated shear box chamber. 


\section{Test procedure and test program}

Two series of saturated and unsaturated suction-controlled tests were conducted to study shear strength characteristics of loess. Regarding saturated tests, soil specimens were installed into the shear box just after preparation. The shear box chamber was sealed and specimens were loaded to the target vertical stress until equilibrium in vertical displacement was achieved. The constant-water content compression stage lasted for 8 to 12 hours. Test specimens were then inundated with de-aired water and settlements were monitored until the end of consolidation stage. Specimens were sheared accordingly at a constant displacement rate of $0.0019 \mathrm{~mm} / \mathrm{min}$ providing drain conditions. After completion of shearing stage, test was terminated and the specimen was dismantled from the box. It was immediately weighed and oven-dried for determination of water content. Details of saturated tests are given in Table 1.

Regarding unsaturated tests, saturated salt solutions were prepared in two batches: one to be used inside the chamber and the other one for putting inside the conventional desiccators. After preparation of test specimens, they were transferred to the desiccators for suction equalization and they were weighed until equilibrium was reached. According to the observations, suction equalization was achieved between three to four weeks. Afterwards, weight and dimensions of test specimens were taken for calculation of void ratio and degree of saturation. Test 
specimens were transferred thereafter to the shear box chamber containing similar salt solution as inside the desiccators and hence the same humidity conditions. It should be noted that specimens shrunk after suction equalization, i.e., they were marginally smaller (1.63\% volumetric strain on average) than the size of shear box. It was not practical to adjust specimen dimensions to fit the shear box unless larger specimens were prepared prior to suction equalization. After setting up the specimen inside the shear box, the temperature and humidity data logger was switched on inside the chamber. The top cap was inserted and chamber was sealed eventually. Before starting the compression stage, the fan was turned on for two hours to assure humidity equalization throughout the chamber. The time period for operation of the fan was decided based on results of two calibration tests as will be presented in the following section. The fan was turned off and the target vertical net stress was applied to the specimen afterwards. After equalization of vertical displacement, compression stage was terminated and shearing stage was initiated. Specimens were sheared at the same rate as that used in saturated tests for consistency and removing the shear rate effects from the results. After shearing stage was completed, measurements of weight and water content were conducted following the same procedure taken in saturated tests. The final water content was used to back-calculate water content and dry density at 
different test stages. Eight unsaturated tests were run in total, details of which are summarized in Table 2.

\section{Interpretation of test results}

\section{Performance of the modified shear box}

Fig. 3 shows variations in relative humidity and suction with time for two calibration tests with and without fan operation. Saturated $\mathrm{NaCl}$ salt solution having the potential $\mathrm{RH}$ and suction of $76 \%$ and $38 \mathrm{MPa}$, respectively, was used at room temperature. Target suction can be achieved within 20 minutes if the fan is turned on while there is a delay in suction equalization of up to 8 hours if the fan is idle. Results confirm the importance of utilizing a fan in agitating the vapor transfer and accelerating the rate of suction equalization. Although using the fan accelerates suction equalization, it may induce some fluctuations in suction at equilibrium. A possible reason is the induced pressure difference by the fan operation. The induced pressure difference between the upstream and the downstream forces the air to move parallel to the shaft. No fluctuations in $\mathrm{RH} /$ suction are expected if the pressure difference is constant. However, any changes in pressure difference would affect the relative vapor pressure and hence suction. Since the steady state testing conditions cannot be controlled precisely during the long period of test (including compression and shearing stages), the fan was switched off 
before compression and shearing stages to prevent undesirable fluctuations in suction. According to this observation, fan was turned on for two hours after setting up the specimens and sealing the shear box chamber to assure uniform distribution of suction. It was then switched off during compression and shearing stages. The steady-state environmental conditions (RH/suction) are further validated by analyzing recorded $\mathrm{RH} / \mathrm{T}$ during compression and shearing phases. Statistical analysis was carried out on measured quantities at $10 \mathrm{~min}$ time intervals for different salt solutions used. The standard deviations in suction were varied from 0.1 to $1.9 \mathrm{MPa}$ for different solutions, confirming good performance of the design in providing stable suction throughout the tests.

\section{Water retention curves}

Water retention properties of recompacted loess in the plane of degree of saturation versus suction were depicted in Fig. 4(a). Data in solid black are related to the equalized hydraulic state of test specimens in the current study. Measured data points of $\mathrm{Ng}$ et al. (2016) for a similar material with an average void ratio of 1.162 were also included in this figure, covering a wider range of suction. Although $\mathrm{Ng}$ et al. (2016) measured water retention curve for both drying and wetting paths, only data along the drying branch were used in this study since all the shear tests conducted on specimens subjected to drying only. This is to remove the hysteresis effect from the 
interpretation of test results. Note that recompacted loess specimen in $\mathrm{Ng}$ et al. (2016) had a slightly higher void ratio than the average void ratio of test specimens in this study. This implies that the test specimens of this study would tend to retain less amount of water at identical suctions. However, data of two studies are in a good agreement at high suctions where adsorption governs water retention behavior, but not capillary forces. Measured data suggest a weak bimodal behavior of water retention curve of recompacted loess, when suction is less than $4 \mathrm{MPa}$. Although a bimodal water retention model (e.g. Zhang and Chen 2005) may provide a better match as compared to a unimodal curve in the low suction range, this may not be true for the high suction range $(>4 \mathrm{MPa})$. For simplicity, the unimodal curve fitting proposed by Fredlund and Xing (1994) is used and shown in Fig. 4(a). It is clear that the predicted and the measured data match fairly well (i.e., $R^{2}=$ 0.998 ) in the high range of suction from 4 to $230 \mathrm{MPa}$. This range of suction is considered for investigating shear behavior of recompacted loess in this study. The model provides a smooth mathematical function for strength analysis. Therefore, the best-fit water retention curve will be used in the following sections for interpreting shear strength characteristics.

Fig. 4(b) shows the corresponding volume changes for both set of data presented in Fig. 4(a). As indicated in Fig. 4(b), the recompacted specimen subjected to wetting and then drying at 
high suctions ( $\mathrm{Ng}$ et al., 2016) suffered from more volume changes compared to the specimens subjected to drying only (this study). Measurements of suction with the small-tip tensiometer clarified the initial suction of $62 \mathrm{kPa}$ for the recompacted specimens. According to the results of this study, specimens subjected to high suctions from the as-compacted state show limited shrinkage strain in the order of $1.6 \%$ which is almost nine times less than corresponding wetting-induced collapse strain (see the following section). This is probably due to the low as-compacted water content $\left(S_{\mathrm{r}}=0.29\right.$ according to Fig. 4(a)), which is at the dry of optimum water content. A smaller amount of shrinkage is expected for a specimen having moisture content of less than the saturated value (Peng and Horn 2007). In addition, the negligible variations in void ratio with suction imply the independence of shrinkage from variations in suction in the range of 8 to $230 \mathrm{MPa}$. This observation suggests suction values beyond $8 \mathrm{MPa}$ are within the residual shrinkage zone with insignificant influence on volume changes. These experimental observations will be used later to highlight the significant role of suction in dilatancy and strength.

\section{Compression behavior}

Fig. 5 shows compression curves of suction-controlled tests in this study up to the vertical net stress of $200 \mathrm{kPa}$ (solid gray symbols). In addition, results of oedometer tests on saturated 
recompacted loess ( $\mathrm{Ng}$ et al. 2016) and an air-dried specimen under laboratory conditions were included for comparison. The test conducted on the saturated recompacted loess is a conventional consolidation test performed in an oedometer. The second test, on the other hand, was carried out in the same device but the specimen was dried first from the as-compacted state in the laboratory environment (air-dried) and then followed by a stepwise compression scheme. The average suction for the air-dried specimen during the test was about 60 MPa. The yield stress of saturated specimen seems to be less than $10 \mathrm{kPa}$ while it is about $490 \mathrm{kPa}$ for the air-dried specimen (solid black symbol). There is a significant increase in yield stress with suction as suction increases from zero to $60 \mathrm{MPa}$, which is consistent with the loading collapse concept of the Barcelona Basic Model (Alonso et al. 1990).

Results of the wetting-induced collapse tests are also included in Fig. 5 for comparison. There is a good agreement between void ratio of the collapse tests and the consolidation curve of the recompacted loess specimen reported by $\mathrm{Ng}$ et al. (2016). All these results reveal that all consolidation data points converge to the same virgin compression curve. According to the results, maximum volumetric collapse strain of up to $13.8 \%$ is achieved under $100 \mathrm{kPa}$ vertical stress. This collapse potential is higher than $6.7 \%$ reported by Jiang et al. (2012) for an artificially structured loess. The artificial loess had an 
additional bonding calcite together with a lower void ratio (1.0) and higher water content (17.7\%) compared to the loess used in this study. According to the results of suction-monitored oedometer tests on compacted silty clay (Jotisankasa et al. 2007), the LC curve shifts towards the right hand side if soil is compacted to the same dry unit weight but with higher compaction water content. In other words, larger collapse is expected for soils compacted to a dryer state under the same stress level.

By looking into the results of suction-controlled compression tests, all specimens show similar behavior (Fig. 5). There is no indication of yield stress up to $200 \mathrm{kPa}$ net stress for the four suction levels considered. Moreover, results of suctioncontrolled tests confirm the similarity between compression behavior of these tests and the unloading branch obtained from oedometer tests (i.e. S0 and U60). These observations imply that all unsaturated tests conducted in this study at high suction range are within the elastic region. The augmentation of yield stress due to suction increase is a well-known fact. Results of compression tests on saturated and unsaturated specimens can be considered as a reference to understand and explain the following shear behavior.

\section{Shear strength and shear behavior}

Results of tests conducted under vertical stress of $50 \mathrm{kPa}$ are depicted in Fig. 6. With regard to shear strength (Fig. 6(a)), 
results of the saturated test show a continuous increase in shear strength with a reduced rate towards a critical state value at horizontal displacement beyond $6 \mathrm{~mm}$. The observed strain hardening behavior, being typical of normally consolidated soils, comes from the post-yield state of the effective consolidation stress. It is noted that saturated specimen was consolidated to the vertical effective stress of $50 \mathrm{kPa}$ and the yield stress of compacted loess was determined to be less than $10 \mathrm{kPa}$. Constant-suction unsaturated tests, however, show a different mode of behavior. There is an initial phase (up to 0.3 $\mathrm{mm}$ ) corresponds to the gap between the cell and the specimen that was created due to the application of suction. The behavior in this phase cannot be attributed to the material since there was almost no change in vertical displacement. Afterwards, a moderate increase in strength (between 0.3 to $1 \mathrm{~mm}$ horizontal displacements) was observed followed by a sharp rise up to a peak for all the tests, representing a higher stiffness compared to the saturated test. The shear strength decreases thereafter towards a relatively constant ultimate state. The peak strength is reached at horizontal displacements less than $1.5 \mathrm{~mm}$ for all the tests. There is a significant increase in shear strength of unsaturated tests compared to the saturated one. More importantly, results of unsaturated tests indicate an increase in both peak and post-peak shear strength with suction even at high suction range considered in this study. For the lower range 
of suction up to $100 \mathrm{kPa}$, Jotisankasa and Mairaing (2010) reported that suction induces stronger bonding at particle contacts and hence specimens become more brittle.

Fig. 6(b) illustrates variations of vertical displacement with horizontal displacement for tests carried out under $50 \mathrm{kPa}$ vertical stress. It is noted that contraction is assumed positive. Similar to the strength behavior, saturated and unsaturated soil specimens show opposite trends in vertical displacement. Saturated specimens continuously contracts as shearing proceeds until the critical state is reached at large displacements, which is typical behavior of normally consolidated soils. In spite of saturated tests, unsaturated specimens initially show a very small contraction (after closing up the gap), followed by noticeable dilation. An accelerated rate of dilation can be seen as suction increases. This is in agreement with the observation of Hossain and Yin (2015) for low range of suction limited to $300 \mathrm{kPa}$. Results also clarify that dilation is still in progress even at horizontal displacements as large as $9 \mathrm{~mm}$, suggesting that critical state may not be achieved yet (Alonso et al. 2007). The critical state is assumed to be reached once no further changes are observed in both volume changes and shear strength as shearing proceeds. It is noted that this condition is only satisfied partly on the shear plane. However, this simplified assumption of the critical state approach should not affect the major conclusions drawn from 
this study. Alsherif and McCartney (2015) also observed that the critical state cannot be achieved for a compacted silt sheared at high suctions and showed a brittle type failure mode. Results of tests conducted under vertical stress of $200 \mathrm{kPa}$ are presented in Fig. 7(a) in terms of shear stress versus horizontal displacement. Trends of change in shear strength are qualitatively similar to those under a lower vertical stress of 50 $\mathrm{kPa}$ (Fig. 6(a)). However, one of the clearest differences is the higher shear strength achieved under elevated vertical stress. As vertical stress increases from $50 \mathrm{kPa}$ to $200 \mathrm{kPa}$, peak shear strength of saturated and unsaturated tests roughly becomes four times and twice, respectively. Moreover, the drop in strength of unsaturated specimens after the peak becomes less significant compared to the case of $50 \mathrm{kPa}$ vertical stress. The observed behavior confirms the overwhelming influence of net stress on dilation rate (Hossain and Yin 2010). Fig. 7(b) indicates variations of vertical displacement with horizontal one under $200 \mathrm{kPa}$ vertical stress. Similar to the case of low stress, the saturated specimen continuously contracts while all unsaturated specimens at high suctions dilate. In addition, the rate of dilation increases with increase of suction from 8 to 230 $\mathrm{MPa}$ during the whole shearing process. Comparing with the results of $50 \mathrm{kPa}$ net stress, Fig. 7(b) clarifies that the rise in net stress from $50 \mathrm{kPa}$ to $200 \mathrm{kPa}$ suppresses the tendency of unsaturated specimens to dilate for all suction levels 
considered. In other words, soil dilation is noticeably lower under $200 \mathrm{kPa}$ net stress compared to $50 \mathrm{kPa}$ one. Moreover, no further tendency for dilation can be seen towards large displacements $(>6 \mathrm{~mm})$ and dilation rate vanishes.

Results of shear strength are explained and discussed in terms of peak shear strength. Fig. 8 depicts maximum shear strength of conducted tests as a function of suction. An increasing trend of peak strength with suction can be observed in most cases under both net stress of $50 \mathrm{kPa}$ and $200 \mathrm{kPa}$. Results of regression analysis clarified that measured data can be well fitted $\left(R^{2}>0.96\right)$ to power laws. This implies the continuous increase of the peak shear strength with suction but at a reduced rate. In contrast to the coarse-grained soils, the contribution of suction to the shear strength would not diminish after the residual suction for an unsaturated fine-grained soil like loess. Nonlinear increase of residual shear strength with suction up to $100 \mathrm{kPa}$ was observed by Hoyos et al. (2014) for silty clayey sand. In spite of numerous studies on strength characteristics of unsaturated soils from low to medium range of suction (less than $1 \mathrm{MPa}$ ), test results within the high suction rage are fairly rare. In the current study, one of the recent modeling approach proposed by Alonso et al. (2010) is used to simulate the observed behavior. In order to improve the contribution of suction to the effective stress, the original $\chi$ parameter in Bishop effective stress equation is replaced by the effective 
degree of saturation in this model. It is to extend the prediction capability of shear strength model to higher range of suction in a more rational way. Therefore, shear strength equation can be expressed as:

$$
\tau=c^{\prime}+\left[\left(\sigma_{v}-u_{a}\right)+S_{r}^{e} \cdot s\right] \tan \phi^{\prime}
$$

where $\tau$ is shear strength, $c^{\prime}$ and $\phi^{\prime}$ are the effective saturated strength parameters, $\sigma_{\mathrm{v}}$ is the total vertical stress, $u_{\mathrm{a}}$ is pore air pressure, $S_{r}^{e}$ is the effective degree of saturation, and $s$ is suction. Based on results of three saturated tests (Table 1), $c^{\prime}$ and $\phi^{\prime}$ were determined as zero and $27.7^{\circ}$, respectively. In order to find the effective degree of saturation, the second proposal (Alonso et al., 2010) as shown in Eq. (2) is adopted here since the first approach is based on a piece-wise function which is more suitable for coarse-grained soils.

$$
S_{r}^{e}=\left(S_{r}\right)^{\alpha}
$$

where $S_{\mathrm{r}}$ is the degree of saturation and $\alpha$ is a material parameter. The best fit curve to the measured water retention data (Fig. 4(a)) is used as $S_{\mathrm{r}}-s$ function. Afterwards, the material parameter, $\alpha$, was back calculated based on a regression analysis to give the best prediction for shear strength (Eq. 1). By analyzing results of 10 saturated and unsaturated tests, the best $\alpha$-value was determined to be 1.76 . Model predictions were compared with measured shear strength data 
and the coefficient of determination was obtained as 0.57 . As shown in Fig. 8, the shear strength increases with an increase in suction, but at a reduced rate. This implies that recompacted loess stiffens as suction increases, which in turn results in an increase of shear strength. However, the model predicts a peak shear strength at the optimum value of $\left(S_{\mathrm{r}}^{e} \cdot s\right)$ followed by a gradual decrease in strength. Theoretically, the shear strength would continue to decrease and eventually reach the saturated shear strength at the maximum theoretical suction of $1000 \mathrm{MPa}$ (corresponding to zero degree of saturation). Although this kind of trend is well suited to the real behavior of coarse-grained soils, it may not perfectly represent the strength of fine-grained soils. The observed trend of peak shear strength with suction at high range supports the idea that leveling off the effective degree of saturation (or Bishop effective stress parameter) towards the end of water retention curve could not be physically valid (Oh and Lu 2014).

\section{Dilatancy}

Dilatancy is studied by applying Eq. (3) to the results presented in previous section as vertical displacement versus horizontal displacement. Data points are selected in such a way that a smooth curve is obtained and hence reliable rates of dilation can be obtained by using:

$$
d=-\frac{\delta V}{\delta H}
$$


where $d$ is dilatancy and $\delta V$ and $\delta H$ are the increments of vertical displacement and horizontal displacement, respectively. Positive values of $d$ represents dilative behavior while negative ones stand for contraction of soil specimens.

The evolution of dilatancy with shear displacement is shown in Fig. 9. Contractive behavior is the characteristic of saturated tests during the whole shearing stage (Hossain and Yin 2010). On the other hand, dilation behavior is dominant for unsaturated specimens throughout shearing except at the initiation of shearing and towards the end. Unsaturated specimens initially show negligible contractive behavior followed by a sharp rise to a peak dilation rate. Afterwards, dilatiancy decreases gradually and eventually vanishes in most cases, being consistent with displacement behavior. Measured dilation rates are compared with three classical stress-dilatancy expressions in the literature as follows:

$$
\begin{aligned}
\left(\tau / \sigma_{n}^{\prime}\right)_{\max } & =\tan \phi_{c s}^{\prime}+\tan \psi_{\text {max }} \\
\left(\tau / \sigma_{n}^{\prime}\right)_{\max } & =\tan \left(\phi_{c s}^{\prime}+\psi_{\max }\right) \\
\left(\tau / \sigma_{n}^{\prime}\right)_{\max } & =\tan \left(\phi_{c s}^{\prime}+0.8 \psi_{\text {max }}\right) \\
\psi & =\tan ^{-1}(d)
\end{aligned}
$$

where $\phi_{c s}^{\prime}$ is the effective critical state friction angle, $\psi$ and $\psi_{\max }$ are the angle of dilation and the maximum angle of dilation, respectively. Eqs. (4a) to $(4 c)$ are known as Taylor (Taylor 1948), Coulomb (Budhu 2008), and Bolton (Bolton 1986) 
failure criteria, respectively. As pointed out by previous researcher, suction needs to be considered as a variable in formulation of stress-dilatancy (e.g. Chiu and Ng 2003; Alonso et al. 2007). Although the definition of stress ratio is straightforward for saturated soils because of the validity of effective stress concept, difficulties arise in defining an appropriate effective stress for unsaturated soils. In order to define a rational stress ratio for unsaturated tests conducted in this study, shear strength is divided by the equivalent vertical effective stress defined as:

$$
\sigma_{e q v}=\left(\sigma_{v}-u_{a}\right)+S_{r}^{e} \cdot s
$$

Fig. 10 shows the rate of dilation at the maximum equivalent effective stress. Note that the maximum equivalent effective stress may not be constant for a test. This is because contraction/dilation induced by shearing can result in a change in the degree of saturation and hence suction. This in turn can lead to a change of $\left(\sigma_{\text {eqv }}\right)_{\max }$ according to Eq. 5. Since there was not any embedded suction sensor into the specimen, the constant-suction condition was assumed at high range $(>8$ $\mathrm{MPa}$ ). For the tests conducted under $200 \mathrm{kPa}$ net stress, most of the data roughly follow the Taylor criterion. On the other hand, results of tests with $50 \mathrm{kPa}$ net stress clearly show scattering of the data mainly on the right hand side of classical models. This observation implies that three examined stress-dilatancy 
equations underestimate the dilation rate of unsaturated specimens at low net stress levels. Wang and Leung (2008) also reported that the original Cam Clay and Rowe's expression (Rowe 1969) overestimate the stress ratio of cemented sand under low confinement if a cohesion term is not incorporated into these models. Similar observation was reported by Cresswell and Powrie (2004) for an uncemented natural sand characterized with a locked fabric having a relative density of $136 \%$. Note that the maximum relative density can be obtained in the laboratory following the standard procedure of ASTM D 4253 is $100 \%$. Regarding current study, there could be two factors causing the scattering of measured data from model predictions. First, the equivalent stress ratio may not fully represent the actual one since it was obtained from a calibrated $\alpha$ with relatively poor coefficient of determination $\left(R^{2}=0.57\right)$. Second and more importantly, the conventional stress-dilatancy equations do not consider the contribution of suction to soil dilation. In order to further study the applicability of saturated models, a different set of unsaturated shear test results from $\mathrm{Ng}$ and Zhou (2005) were also examined. Data were re-interpreted following the same methodology used for compacted loess in this study. In other words, the best fit water retention curve of completely decomposed granite (CDG) was used to calibrate the material parameter, $\alpha$, in the framework of microstructuralbased effective stress through curve fitting of measured shear 
strength data at different suction levels. The equivalent effective stress was then calculated by using Eq. 5. Results are presented in Fig. 10 together with the empirical stress-dilatancy equation of Bolton (1986) for the purpose of comparison. Deviation of measurements from prediction can be also found for the unsaturated silty sand.

\section{Significance of suction}

Fig. 11 shows variations in maximum dilatancy with suction. The maximum dilatancy was obtained from results of Fig. 9. Results are also represented in terms of maximum dilation angle calculated by the following expression:

$$
\psi_{\max }=\tan ^{-1}\left(d_{\max }\right)
$$

In order to distinguish between the roles played by suction and void ratio on dilatancy, void ratio of test specimens is also depicted in the figure. According to the results of Fig. 11, there is a linear trend of increase in dilatancy as well as the angle of dilation with suction for both net stress considered within the high suction range. The trend of variations in dilatancy with suction is similar to those shown in Fig. 8 for shear strength. In other words, the dilatancy shows a rapid increase from zero suction (the maximum dilatancy is zero for saturated tests) to 8 $\mathrm{MPa}$ and then followed by a linear relationship with a gentler slope towards the suction value of $230 \mathrm{MPa}$. In spite of 
negligible influence of suction on dilatancy of compacted gravels of limestone (Alonso et al. 2007), suction effect is quite significant on dilation rate of compacted loess. The unsaturated specimens compressed to $50 \mathrm{kPa}$ net stress give a consistently higher dilatancy than those compressed to $200 \mathrm{kPa}$. The observed trends clarify that for the suction range considered in this study, the average rate of increase in dilation with suction is 0.02 and $0.06^{\circ} / \mathrm{MPa}$ for tests carried out under $50 \mathrm{kPa}$ and $200 \mathrm{kPa}$, respectively. In addition, measurements of volume change after suction equalization stage clarified insignificance of suction beyond $8 \mathrm{MPa}$ on changes in void ratio (Fig. 4(b)). The numbers indicated in Fig. 11 are corresponding void ratio of soil specimens before shearing stage. The maximum difference in void ratio is less than 0.03 and 0.01 for tests conducted under $50 \mathrm{kPa}$ and $200 \mathrm{kPa}$ net stress, respectively. However, the enhancement of dilatancy with suction is considerable and cannot be neglected. An increase of suction beyond the maximum past value would result in a considerable increase in the initial stiffness (Vassallo et al. 2007). Furthermore, the enhancement of suction can induce an aggregated microstructure (Merchán et al. 2011). This implies that as specimens become dryer, larger aggregates would be created. A higher dilatancy is thus expected for a soil with larger and stiffer particles/aggregates. Therefore, an increase of suction would enhance soil dilation even at high suctions. 


\section{Summary and conclusions}

Two series of saturated and constant-suction unsaturated direct shear tests were carried out to investigate compression behavior as well as shear strength characteristics of compacted loess. A shear box chamber was modified based on the vapor equilibrium technique to control suction within the high range from 8 to $230 \mathrm{MPa}$. The following conclusions can be drawn based on results of the current laboratory study:

1) Compacted unsaturated loess suffers from significant volume contraction due to wetting. Collapse potential in terms of volumetric strain reaches $14 \%$ under $100 \mathrm{kPa}$ vertical effective stress. Larger collapse observed compared to similar soils reported in the literature is attributed to higher void ratio. However, volume changes under constantsuction conditions are insignificant (up to the net stress of $200 \mathrm{kPa}$ ) and within the elastic region of suction-induced desiccated specimens. Moreover, suction-induced volumetric shrinkage is $1.6 \%$ on average which is almost one order of magnitude less than that of wetting-induced collapse.

2) In contrast to the saturated test results, strain softening mode of failure associated with dilation is observed for unsaturated specimens at high suction range. The peak strength, mostly achieved at the horizontal displacement of 1 2 $\mathrm{mm}$, continuously increases with suction but at a 
reduced rate. The increasing trend of peak strength cannot be predicted by the microstructural-based effective stress framework. One possible reason is that the model diminishes the contribution of high suction to strength towards the tail of water retention curve at which degree of saturation is close to zero.

3) The increase of suction enhances the dilation rate under both net stresses of 50 and $200 \mathrm{kPa}$. This observation reveals the significance of suction in inducing dilation even at high range which cannot be captured by existing models. In most cases, the dilatancy at the equivalent peak stress ratio is higher than the predictions of stress-dilatancy equations for saturated granular soils. This confirms the necessity of considering suction contributions in dilatancy formulations.

4) Within the suction range of 8 to $230 \mathrm{MPa}$, dilatancy increases with suction in a linear fashion. Results show that dilatancy increases with suction at rates of $0.02^{\circ} / \mathrm{MPa}$ and $0.06^{\circ} / \mathrm{MPa}$ for specimens compressed to 50 and $200 \mathrm{kPa}$ net stress, respectively. It should be also noted that differences in void ratio of unsaturated specimens before shearing is less than 0.03 , implying the independent role of suction in enhancing dilation.

\section{Acknowledgments}


The financial support provided by the Research Grants Council of the Hong Kong Special Administrative Region (HKSAR) through the research grant No. 616812 is greatly appreciated. The second author is also grateful to Mr André Archer and $\mathrm{Mr}$ Sina Baghbanrezvan for their heartfelt assistance in conducting some experiments reported here.

\section{Notation}

The following symbols are used in this paper:

$a$

$c^{\prime}$

$d$

$e$

$m$

$n$

$R C$

RH Relative humidity

$R^{2} \quad$ Coefficient of determination

$S$

$S_{r}^{e} \quad$ Effective degree of saturation

$S_{\mathrm{r}} \quad$ Degree of saturation

$T \quad$ Temperature

$u_{\mathrm{a}} \quad$ Pore air pressure

$w_{\mathrm{opt}} \quad$ Standard Proctor optimum water content

$\alpha \quad$ Material parameter 


$\begin{array}{ll}\left(\gamma_{\mathrm{d}}\right)_{\max } & \text { Maximum dry unit weight } \\ \delta H & \text { Increment of horizontal displacement } \\ \delta V & \text { Increment of vertical displacement } \\ \varepsilon_{\mathrm{v}} & \text { Volumetric strain } \\ \sigma_{\text {eqv }} & \text { Equivalent vertical effective stress } \\ \sigma_{\mathrm{n}}^{\prime} & \text { Effective normal stress } \\ \sigma_{\mathrm{v}} & \text { Net vertical stress } \\ \sigma_{\mathrm{v}}^{\prime} & \text { Effective vertical stress } \\ \tau & \text { Shear stress } \\ \phi_{c s}^{\prime} & \text { Effective critical state friction angle } \\ \chi & \text { Material parameter in Bishop effective stress } \\ \psi & \text { Angle of dilation } \\ \psi_{\mathrm{r}} & \text { Residual suction }\end{array}$

\section{References}

Akbari Garakani, A., Haeri, S. M., Khosravi, A. and Habibagahi, G. 2015. Hydro-Mechanical Behavior of Undisturbed Collapsible Loessial Soils Under Different Stress State Conditions. Engineering Geology, 195, 28-41.

Alonso, E. E., Gens, A. and Josa, A. 1990. A Constitutive Model for Partially Saturated Soils. Géotechnique, 40(3), 405-430. 
Alonso, E. E., Iturralde, E. F. O. and Romero, E. E. 2007. Dilatancy of Coarse Granular Aggregates. Experimental Unsaturated Soil Mechanics, Springer, 119-135.

Alonso, E. E., Pereira, J., Vaunat, J. and Olivella, S. 2010. A Microstructurally Based Effective Stress for Unsaturated Soils. Géotechnique, 60(12), 913-925.

Alsherif, N. A., and McCartney, J. S. 2014. Effective Stress in Unsaturated Silt at Low Degrees of Saturation. Vadose Zone Journal, 13(5).

Alsherif, N. A., and McCartney, J. S. 2015. Thermal behaviour of unsaturated silt at high suction magnitudes. Géotechnique, 65(9), 703-716.

ASTM. 2011. Standard practice for classification of soils for engineering purposes (Unified Soil Classification System). ASTM standard D2487. American Society for Testing and Materials, West Conshohocken, Pa.

ASTM. 2002. Standard test method for maximum index density and unit weight of soils using a vibratory table. ASTM standard D4253. American Society for Testing and Materials, West Conshohocken, Pa.

Blatz, J. A., Cui, Y. and Oldecop, L. 2008. Vapour Equilibrium and Osmotic Technique for Suction Control. Geotechnical and Geological Engineering, 26(6), 661-673.

Bolton, M. 1986. The Strength and Dilatancy of Sands. Géotechnique, 37(2). 
Budhu, M. 2008. Soil mechanics and foundations, (with CD), John Wiley \& Sons.

Chiu, C. F., and Ng, C. W. W. 2003. A State-Dependent ElastoPlastic Model for Saturated and Unsaturated Soils. Géotechnique, 53(9), 809-829.

Cresswell, A., and Powrie, W. 2004. Triaxial Tests on an Unbonded Locked Sand. Géotechnique, 54(2), 107-115.

Fredlund, D. G., and Xing, A. 1994. Equations for the SoilWater Characteristic Curve. Canadian Geotechnical Journal, 31(4), 521-532.

Goh, S. G., Rahardjo, H., and Leong, E. C. 2010. Shear strength equations for unsaturated soil under drying and wetting. Journal of Geotechnical and Geoenvironmental Engineering, ASCE, 136(4), 594-606.

Goh, S. G., Rahardjo, H., and Leong, E. C. 2014. Shear strength of unsaturated soils under multiple drying-wetting cycles. Journal of Geotechnical and Geoenvironmental Engineering, ASCE, 140(2), p.06013001.

Heitor, A., Indraratna, B., and Rujikiatkamjorn, C. 2013. Laboratory study of small-strain behavior of a compacted silty sand. Canadian Geotechnical Journal, 50(2), 179-188.

Hossain, M. A., and Yin, J. H. 2010. Behavior of a compacted completely decomposed granite soil from suction controlled direct shear tests. Journal of Geotechnical and Geoenvironmental Engineering, ASCE, 136(1), 189-198. 
Hossain, M. A., and Yin, J. H. 2015. Dilatancy and Strength of an Unsaturated Soil-Cement Interface in Direct Shear Tests. International Journal of Geomechanics, 15(5).

Hoyos, L. R., Velosa, C. L. and Puppala, A. J. 2014. Residual Shear Strength of Unsaturated Soils Via Suction-Controlled Ring Shear Testing. Engineering Geology, 172, 1-11.

Jiang, M., Hu, H., and Liu, F. 2012. Summary of Collapsible Behaviour of Artificially Structured Loess in Oedometer and Triaxial Wetting Tests. Canadian Geotechnical Journal, 49(10), 1147-1157.

Jotisankasa, A., and Mairaing, W. 2010. Suction-Monitored Direct Shear Testing of Residual Soils from Landslide-Prone Areas. Journal of Geotechnical and Geoenvironmental Engineering, ASCE, 136(3), 533-537.

Jotisankasa, A., Ridley, A. and Coop, M. 2007. Collapse behavior of compacted silty clay in suction-monitored oedometer apparatus. Journal of Geotechnical and Geoenvironmental Engineering, ASCE, 133(7), 867-877.

Lu, N., and Likos, W. J. 2006. Suction Stress Characteristic Curve for Unsaturated Soil. Journal of Geotechnical and Geoenvironmental Engineering, ASCE, 132(2), 131-142.

Melinda, F., Rahardjo, H., Han, K. K., and Leong, E. C. 2004. Shear Strength of Compacted Soil Under Infiltration Condition. Journal of Geotechnical and Geoenvironmental Engineering, ASCE, 130(8), 807-817. 
Merchán, V., Romero, E., and Vaunat, J. 2011. An Adapted Ring Shear Apparatus for Testing Partly Saturated Soils in the High Suction Range. Geotechnical Testing Journal, $34(5)$.

Muñoz-Castelblanco, J. A., Delage, P., Pereira, J. M., and Cui, Y. J. 2012. On-Sample Water Content Measurement for a Complete Local Monitoring in Triaxial Testing of Unsaturated Soils. Géotechnique, 62(7), 595-604.

Ng, C. W. W. 2014. Humidity and Osmotic Suction-Controlled Box. U.S. Patent No. 8,800,353. Washington, DC: U.S. Patent and Trademark Office.

Ng, C. W. W., and Chiu, C. F. 2003. Laboratory Study of Loose Saturated and Unsaturated Decomposed Granitic Soil. Journal of Geotechnical and Geoenvironmental Engineering, ASCE, 129(6), 550-559.

Ng, C. W. W., Sadeghi, H., Hossen, S. B., Chiu, C., Alonso, E. E., and Baghbanrezvan, S. 2016. Water Retention and Volumetric Characteristics of Intact and Recompacted Loess. Canadian Geotechnical Journal, 53(12), 1258-1269.

Ng, C. W. W., and Xu, J. 2012. Effects of current suction ratio and recent suction history on small strain behaviour of an unsaturated soil. Canadian Geotechnical Journal, 49(2), 226-243.

Ng, C. W. W., and Zhou, R. Z. B. 2005. Effects of soil suction on dilatancy of an unsaturated soil. Proceedings of the 16th 
International Conference on Soil Mechanics and Geotechnical Engineering. Asaka, Japan, Millpress, Rotterdam, vol. 2:559-562.

Nishimura, T., and Fredlund, D. 2001. Failure envelope of a desiccated, unsaturated silty soil. Proc., Proceedings of the Fifteenth International Conference on Soil Mechanics and Geotechnical Engineering, Istanbul, Turkey, 27-31 August 2001. Volumes 1-3. AA Balkema, , 615-618.

Oh, S., and Lu, N. 2014. Uniqueness of the Suction Stress Characteristic Curve Under Different Confining Stress Conditions. Vadose Zone Journal, 13(5).

Peng, X., and Horn, R. 2007. Anisotropic shrinkage and swelling of some organic and inorganic soils. European Journal of Soil Science, 58(1), 98-107.

Pineda, J. A., Romero, E., De Gracia, M., and Sheng, D. 2014. Shear Strength Degradation in Claystones due to Environmental Effects. Géotechnique, 64(6), 493-501.

Rowe, P. W. 1969. The relation between the shear strength of sands in triaxial compression, plane strain and direct shear. Géotechnique, 19(1), 75-86.

Tang, A. M. and Cui, Y. J. 2005. Controlling suction by the vapour equilibrium technique at different temperatures and its application in determining the water retention properties of MX80 clay. Canadian Geotechnical Journal, 42(1), 287296. 
Taylor, D. W. 1948. Fundamentals of Soil Mechanics. Soil Science, 66(2), 161.

Vassallo, R., Mancuso, C., and Vinale, F. 2007. Effects of net stress and suction history on the small strain stiffness of a compacted clayey silt. Canadian geotechnical journal, 44(4), 447-462.

Wang, Y. H., and Leung, S. C. 2008. Characterization of Cemented Sand by Experimental and Numerical Investigations. Journal of Geotechnical and Geoenvironmental Engineering, ASCE, 134(7), 992-1004.

Zhan, L. T. 2003. Field and laboratory study of an unsaturated expansive soil associated with rain-induced slope instability. Ph.D. thesis, The Hong Kong University of Science and Technology, Hong Kong.

Zhan, T. L., and Ng, C. W. W. 2006. Shear Strength Characteristics of an Unsaturated Expansive Clay. Canadian Geotechnical Journal, 43(7), 751-763.

Zhang, L., and Chen, Q. 2005. Predicting bimodal soil-water characteristic curves. Journal of Geotechnical and Geoenvironmental Engineering, ASCE, 131(5), 666-670. 
Table 1. Summary of test program and conditions for saturated tests

\begin{tabular}{llll}
\hline $\begin{array}{l}\text { Test } \\
\text { identity }\end{array}$ & $\begin{array}{l}\text { Initial void } \\
\text { ratio } \\
e_{0}\end{array}$ & $\begin{array}{l}\text { Initial degree } \\
\text { of saturation } \\
S_{\mathrm{r} 0}\end{array}$ & $\begin{array}{l}\text { Vertical } \\
\sigma_{\mathrm{v}}(\mathrm{kPa})\end{array}$ \\
\hline $\mathrm{S} 50$ & 1.111 & 0.29 & 50.4 \\
$\mathrm{~S} 100$ & 1.114 & 0.29 & 100.3 \\
$\mathrm{~S} 200$ & 1.085 & 0.30 & 199.9 \\
\hline
\end{tabular}


Table 2. Summary of test program and conditions for unsaturated tests

\begin{tabular}{lllll}
\hline $\begin{array}{l}\text { Test } \\
\text { identity }\end{array}$ & $\begin{array}{l}\text { Initial void Initial degree Vertical net } \\
\text { ratio } \\
\text { of saturation }\end{array}$ & $\begin{array}{l}\text { Suction } \\
\text { stress } \\
e_{0}(\mathrm{MPa})\end{array}$ & $\sigma_{\mathrm{v}}-u_{\mathrm{a}}(\mathrm{kPa})$ & \\
\hline $\mathrm{U} 50-8$ & 1.090 & 0.29 & & 13.0 \\
$\mathrm{U} 50-40$ & 1.091 & 0.29 & 50.4 & 35.6 \\
$\mathrm{U} 50-125$ & 1.103 & 0.30 & & 128.9 \\
$\mathrm{U} 50-230$ & 1.092 & 0.29 & & 231.1 \\
$\mathrm{U} 200-8$ & 1.108 & 0.31 & & 6.4 \\
$\mathrm{U} 200-40$ & 1.095 & 0.29 & 199.9 & 37.1 \\
$\mathrm{U} 200-125$ & 1.094 & 0.29 & & 121.9 \\
$\mathrm{U} 200-230$ & 1.092 & 0.29 & & 228.9 \\
\hline
\end{tabular}




\section{Figure captions:}

Fig. 1. Compaction curve of loess

Fig. 2. Schematic layout of the modified direct shear box apparatus

Fig. 3. Performance of the isolated shear box chamber in achieving the target $\mathrm{RH} /$ suction

Fig. 4. Variations in (a) degree of saturation, and (b) void ratio with suction

Fig. 5. Compression curves of saturated and unsaturated recompacted loess

Fig. 6. Variations in (a) shear stress, and (b) vertical displacement with horizontal displacement for vertical stress of $50 \mathrm{kPa}$

Fig. 7. Variations in (a) shear stress, and (b) vertical displacement with horizontal displacement for vertical stress of $200 \mathrm{kPa}$

Fig. 8. Variations in peak shear strength with suction

Fig. 9. Variations in dilatancy with horizontal displacement under vertical stress of (a) $50 \mathrm{kPa}$, and (b) $200 \mathrm{kPa}$

Fig. 10. Dilatancy at the equivalent peak stress ratio

Fig. 11. The influence of suction on maximum dilatancy of recompacted loess. 


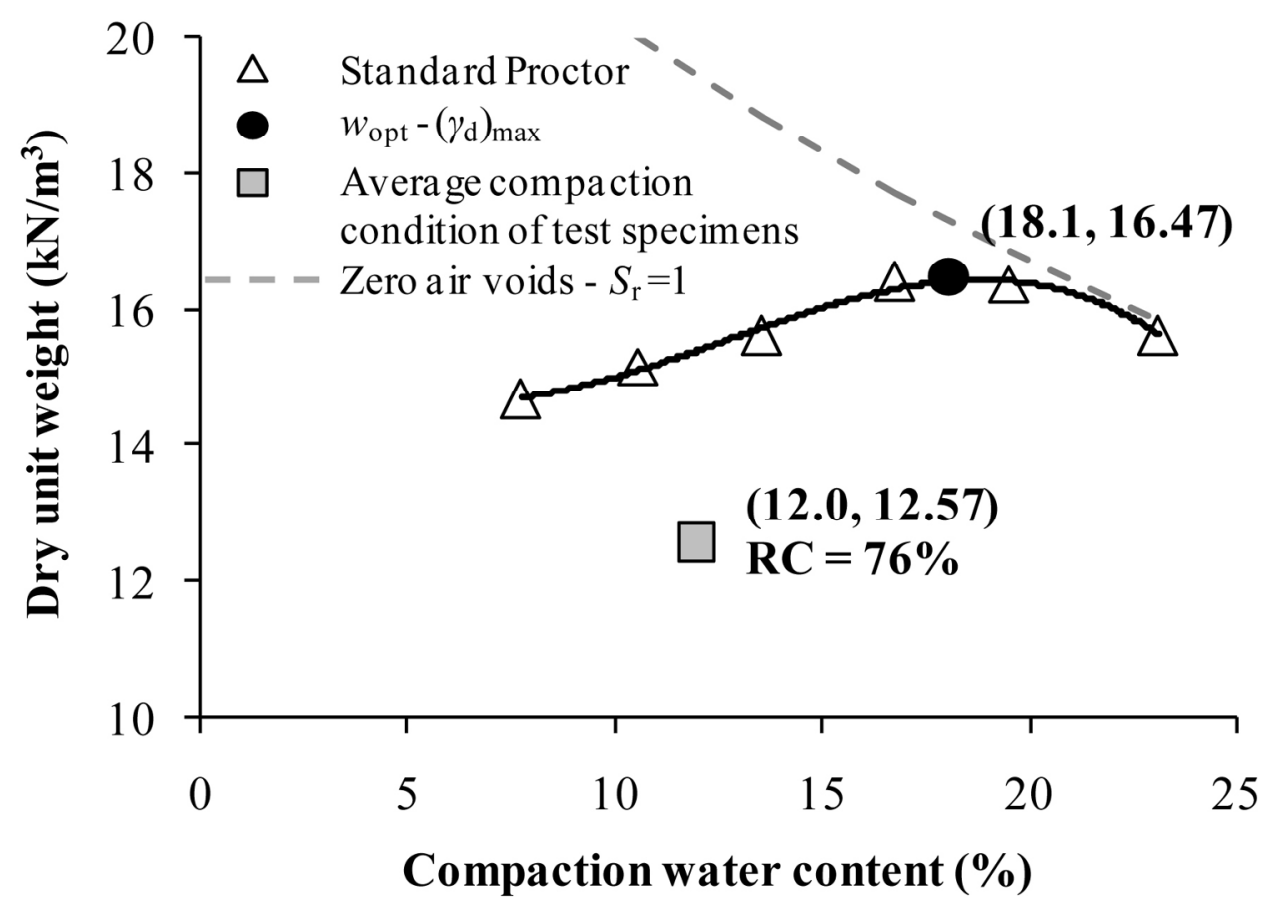

Fig. 1. Compaction curve of loess

$157 \times 107 \mathrm{~mm}(300 \times 300$ DPI $)$ 


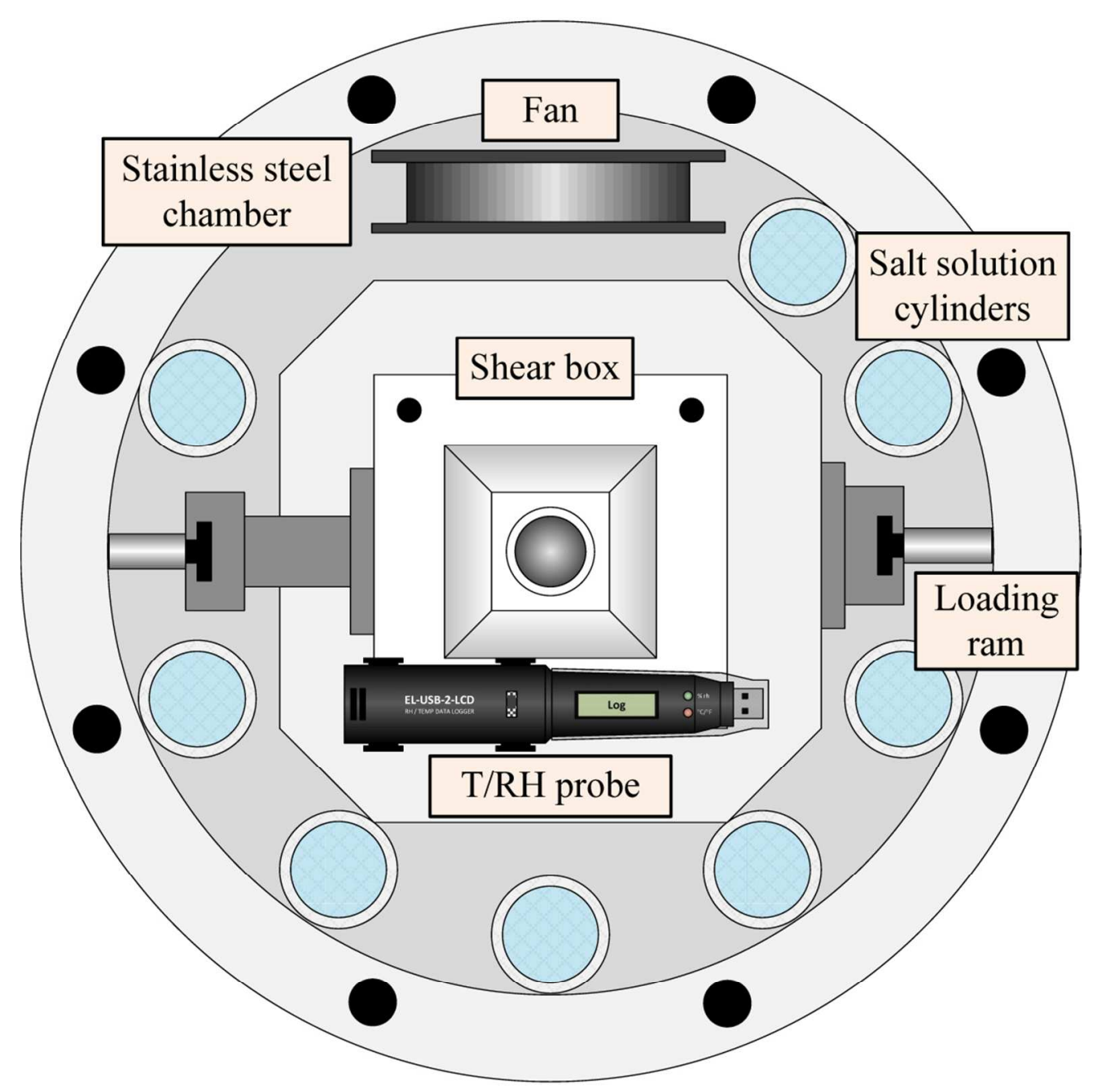

Fig. 2. Schematic layout of the modified direct shear box apparatus $100 \times 101 \mathrm{~mm}(300 \times 300$ DPI $)$ 


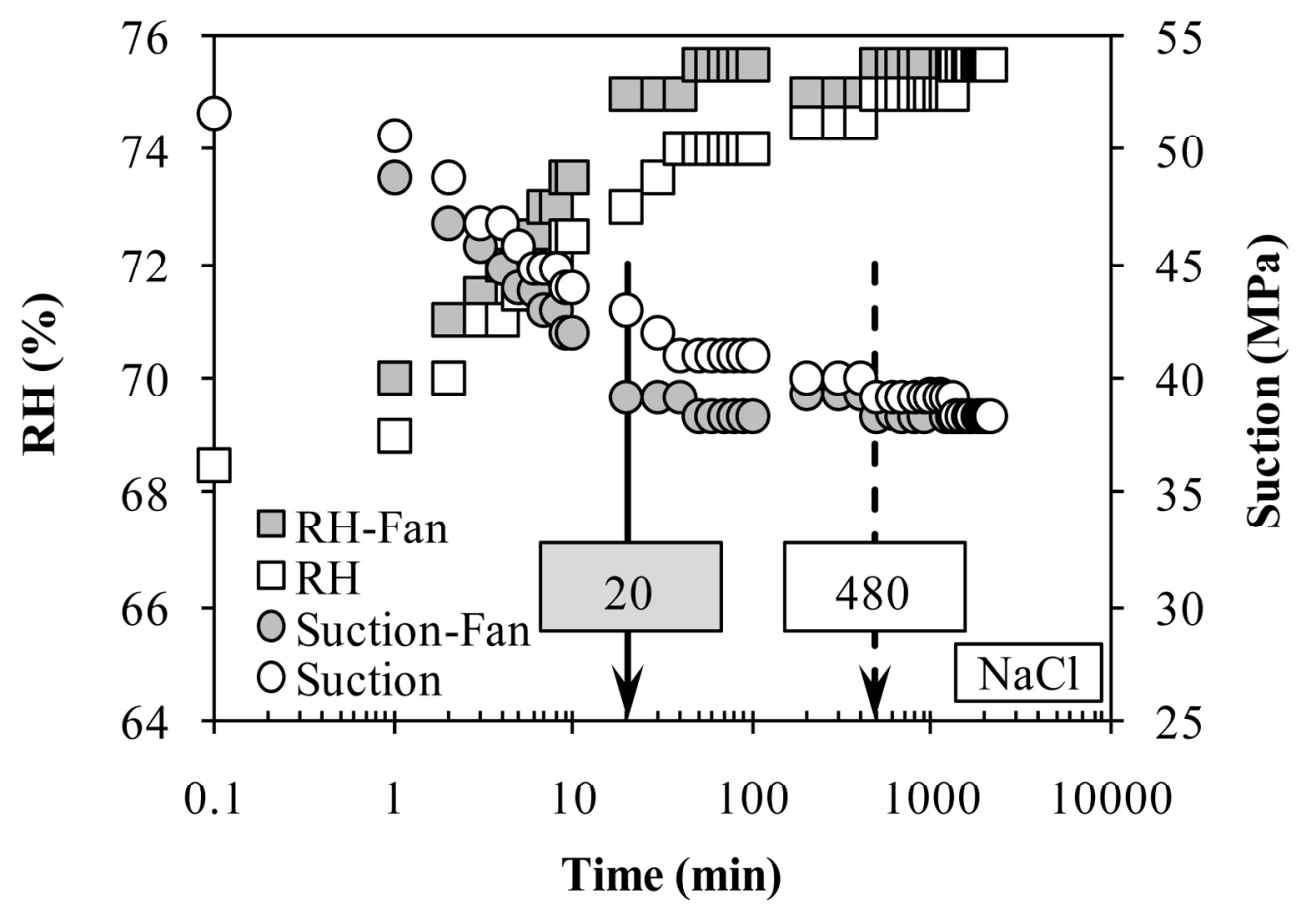

Fig. 3. Performance of the isolated shear box chamber in achieving the target RH/suction $157 \times 109 \mathrm{~mm}(300 \times 300 \mathrm{DPI})$ 


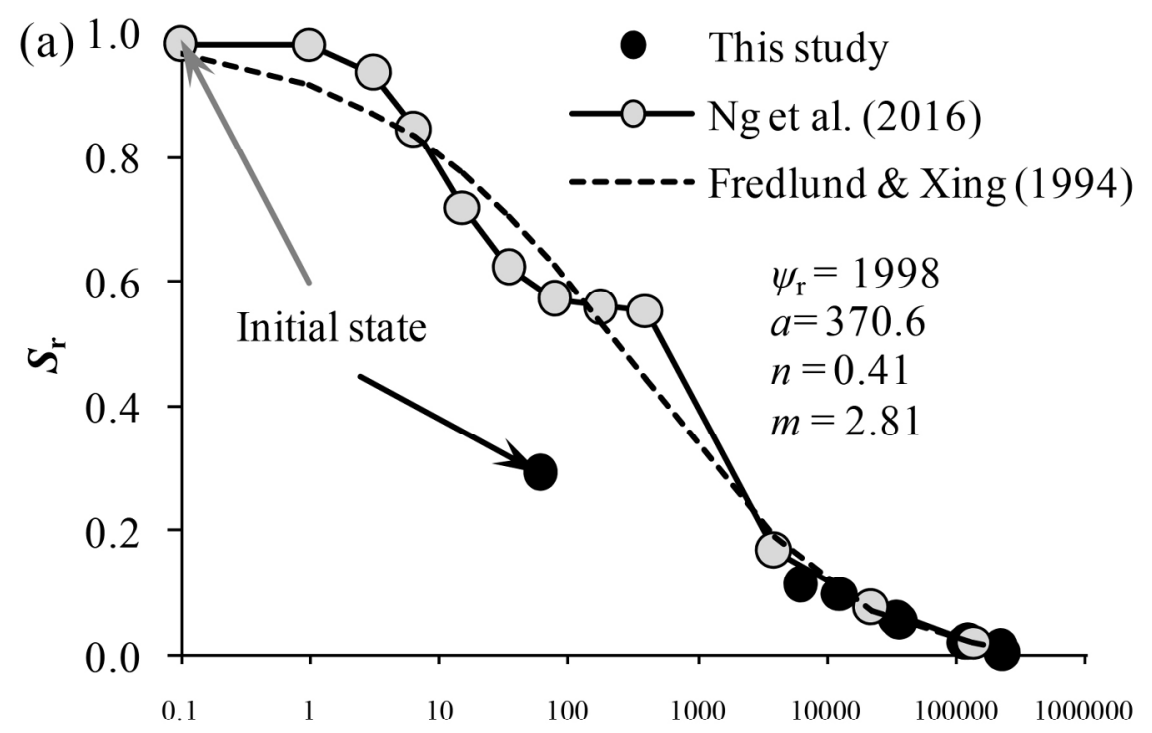

(b)

Suction (kPa)

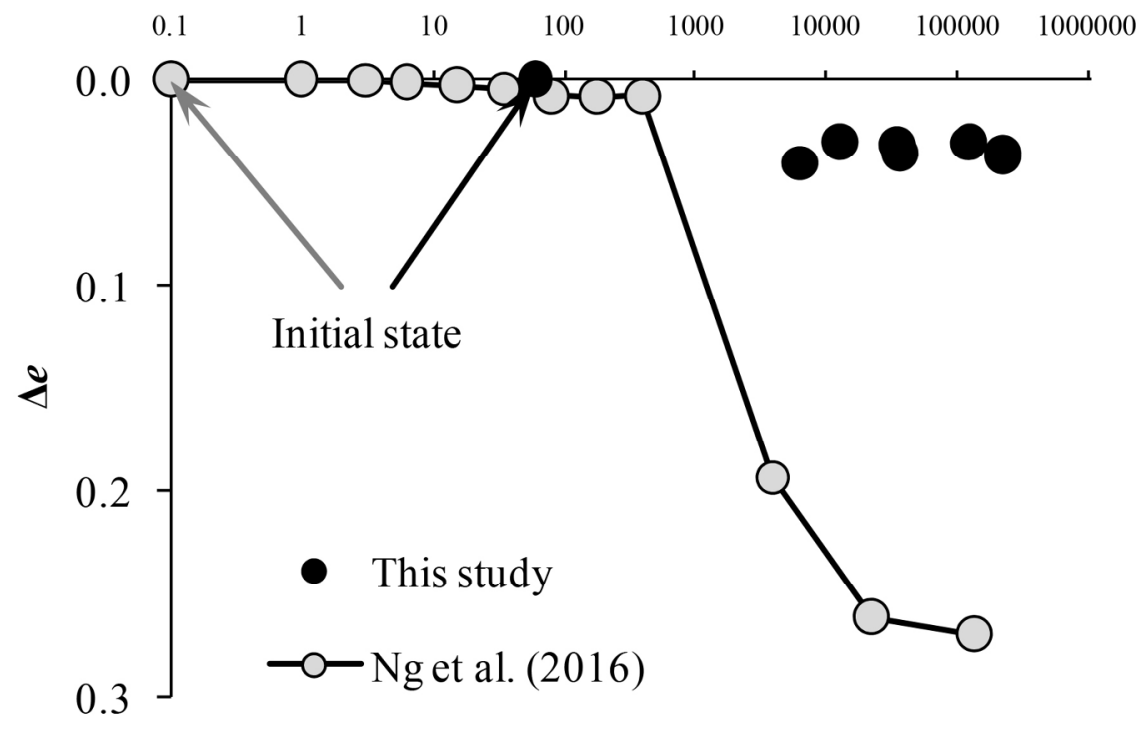

Fig. 4. Variations in (a) degree of saturation, and (b) void ratio with suction $155 \times 206 \mathrm{~mm}(300 \times 300 \mathrm{DPI})$ 


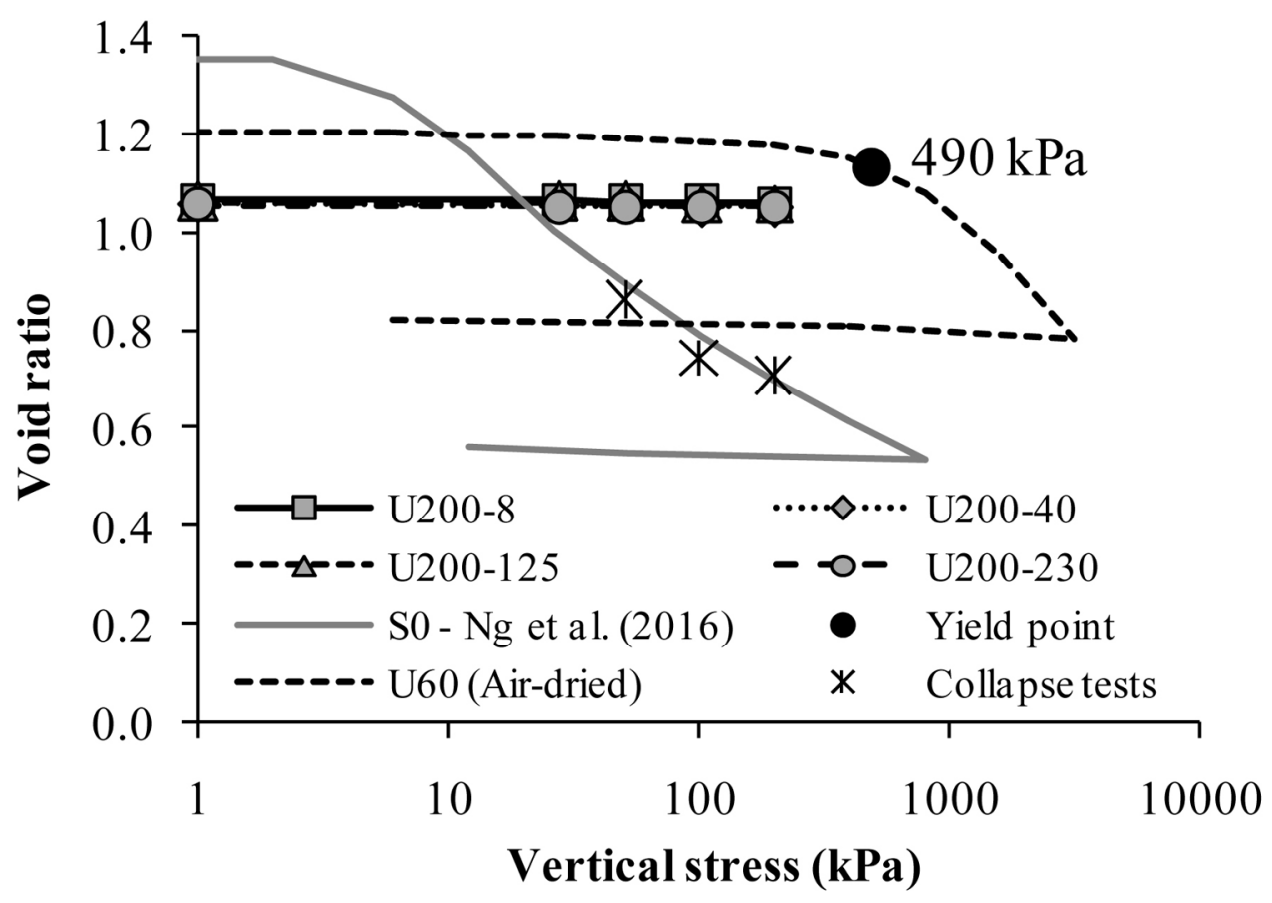

Fig. 5. Compression curves of saturated and unsaturated recompacted loess $157 \times 107 \mathrm{~mm}(300 \times 300 \mathrm{DPI})$ 

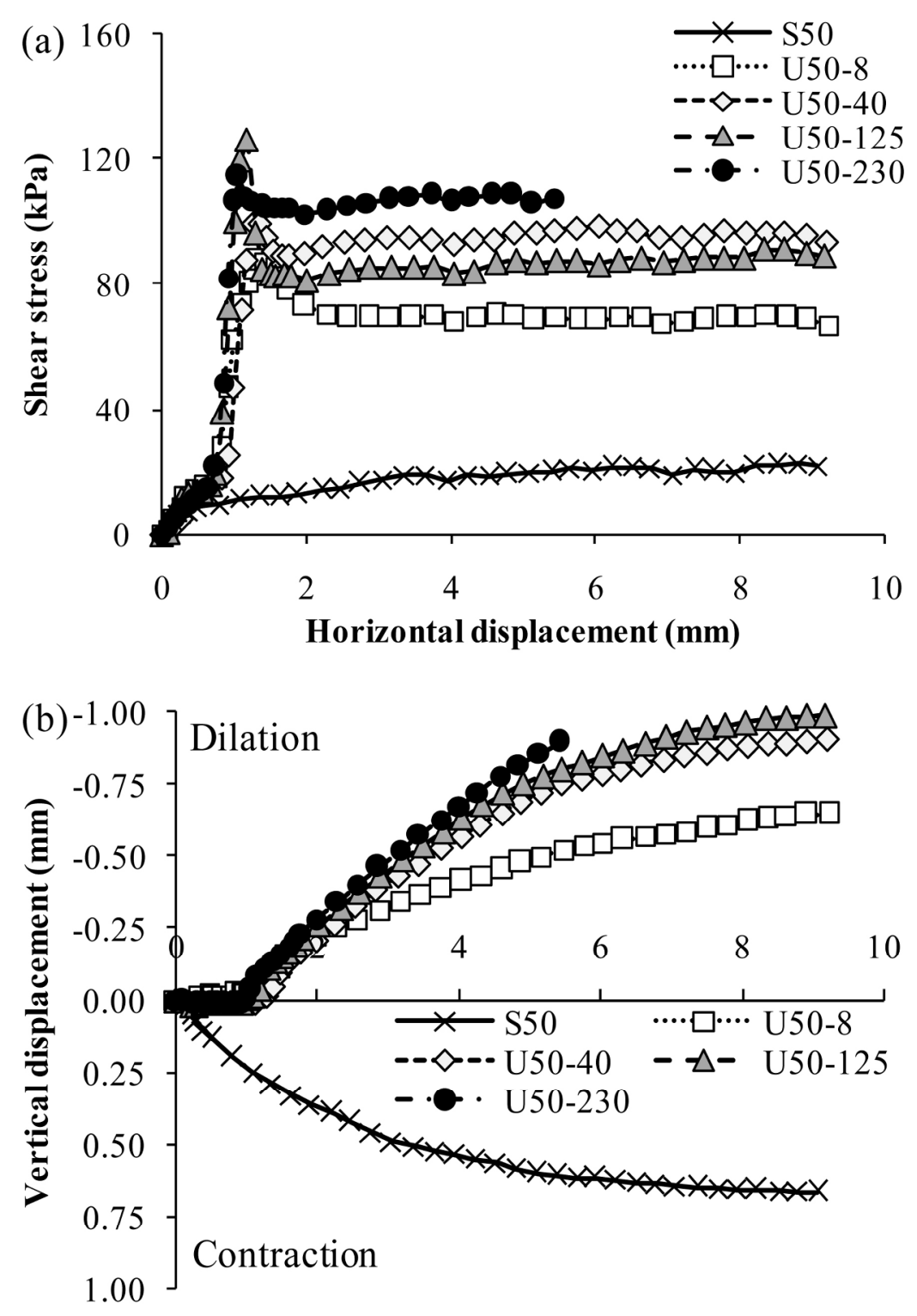

\section{Horizontal displacement (mm)}

Fig. 6. Variations in (a) shear stress, and (b) vertical displacement with horizontal displacement for vertical stress of $50 \mathrm{kPa}$

$155 \times 227 \mathrm{~mm}(300 \times 300 \mathrm{DPI})$ 

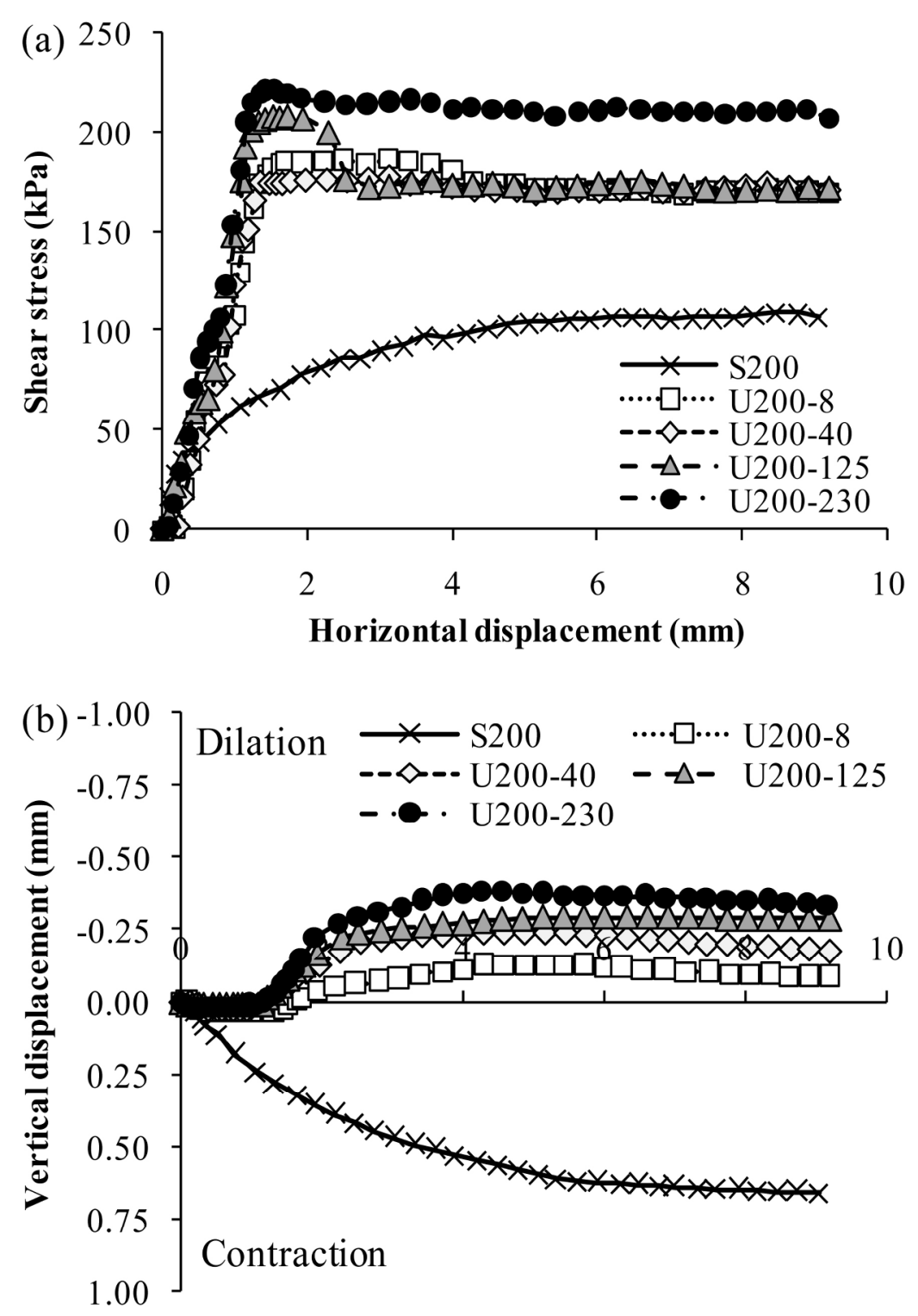

\section{Horizontal displacement (mm)}

Fig. 7. Variations in (a) shear stress, and (b) vertical displacement with horizontal displacement for vertical stress of $200 \mathrm{kPa}$

$155 \times 227 \mathrm{~mm}(300 \times 300 \mathrm{DPI})$ 


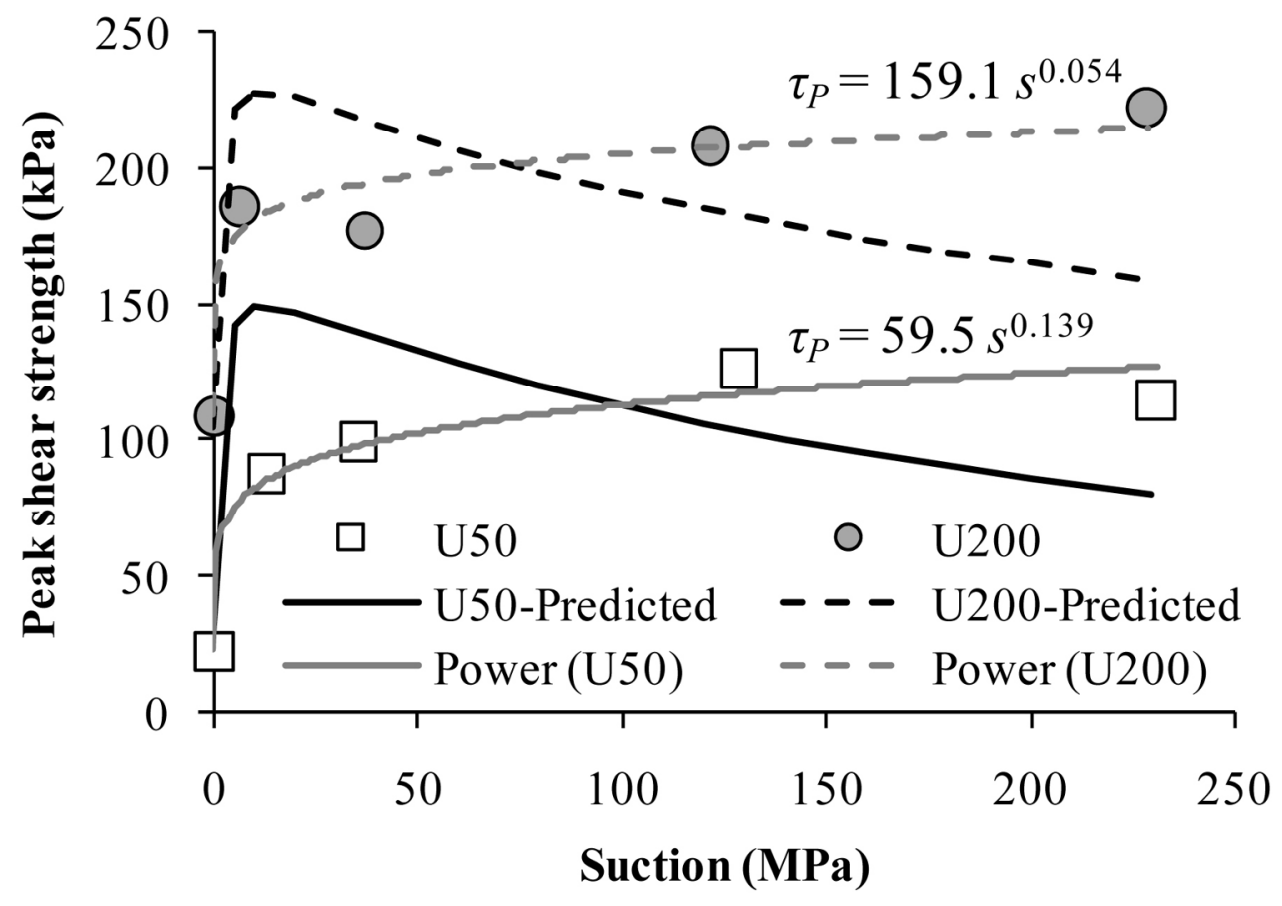

Fig. 8. Variations in peak shear strength with suction $157 \times 107 \mathrm{~mm}(300 \times 300 \mathrm{DPI})$ 


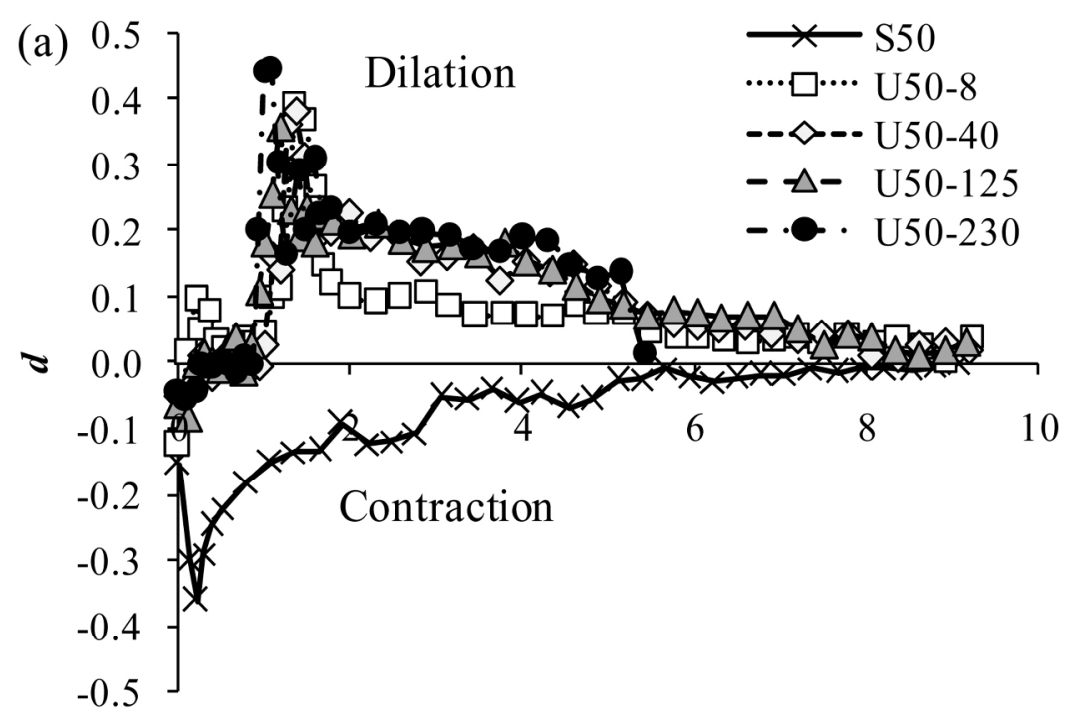

\section{Horizontal displacement (mm)}

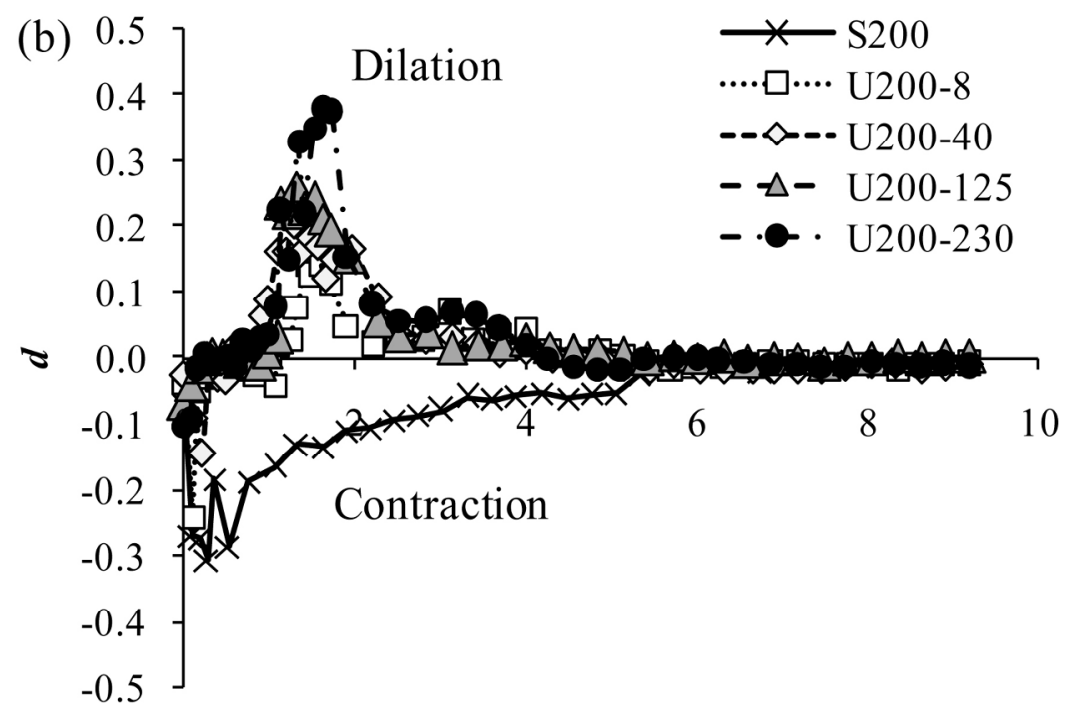

\section{Horizontal displacement (mm)}

Fig. 9. Variations in dilatancy with horizontal displacement under vertical stress of (a) $50 \mathrm{kPa}$, and (b) 200 $\mathrm{kPa}$

$155 \times 224 \mathrm{~mm}(300 \times 300 \mathrm{DPI})$ 


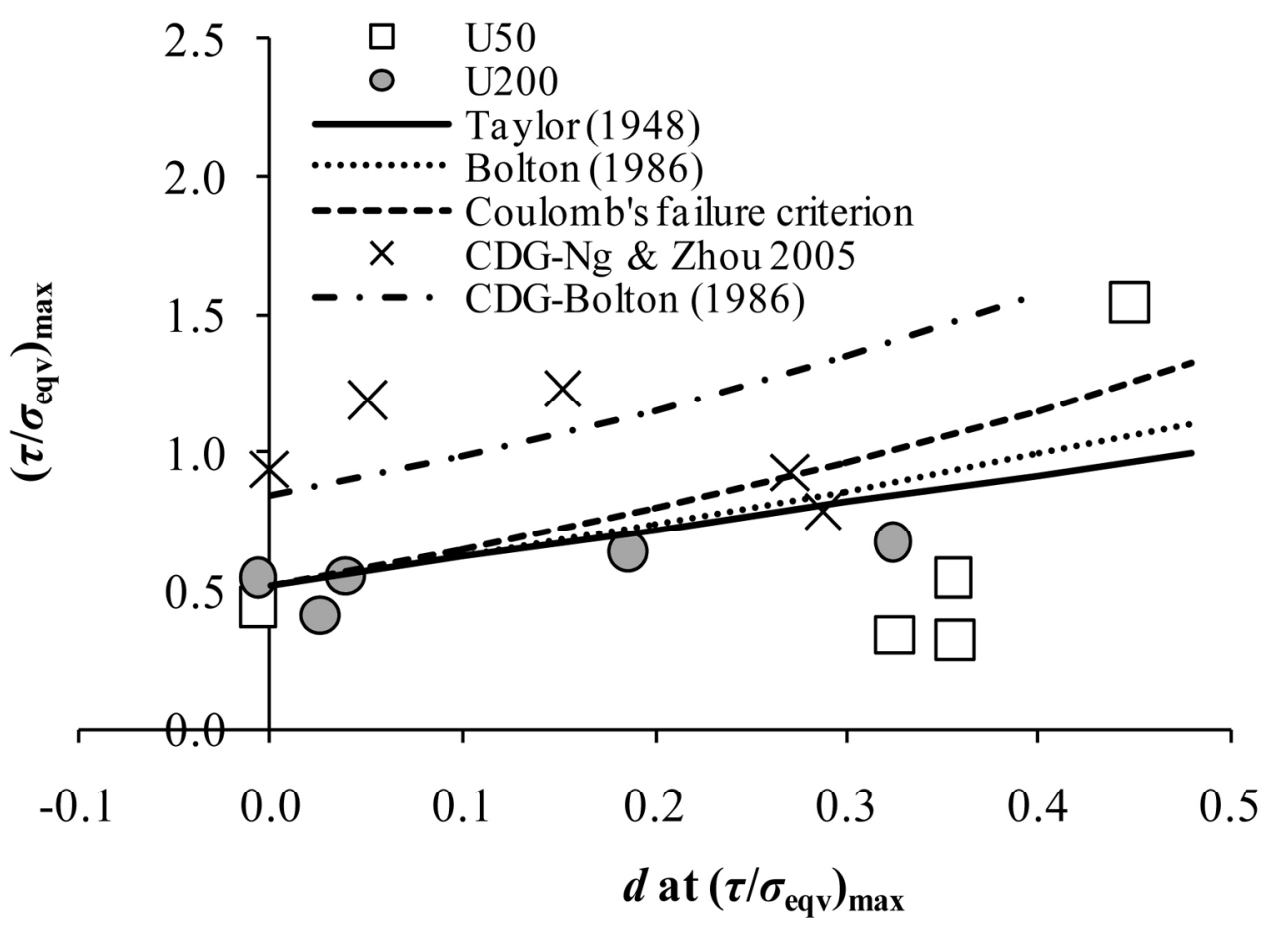

Fig. 10. Dilatancy at the equivalent peak stress ratio $157 \times 110 \mathrm{~mm}(300 \times 300 \mathrm{DPI})$ 


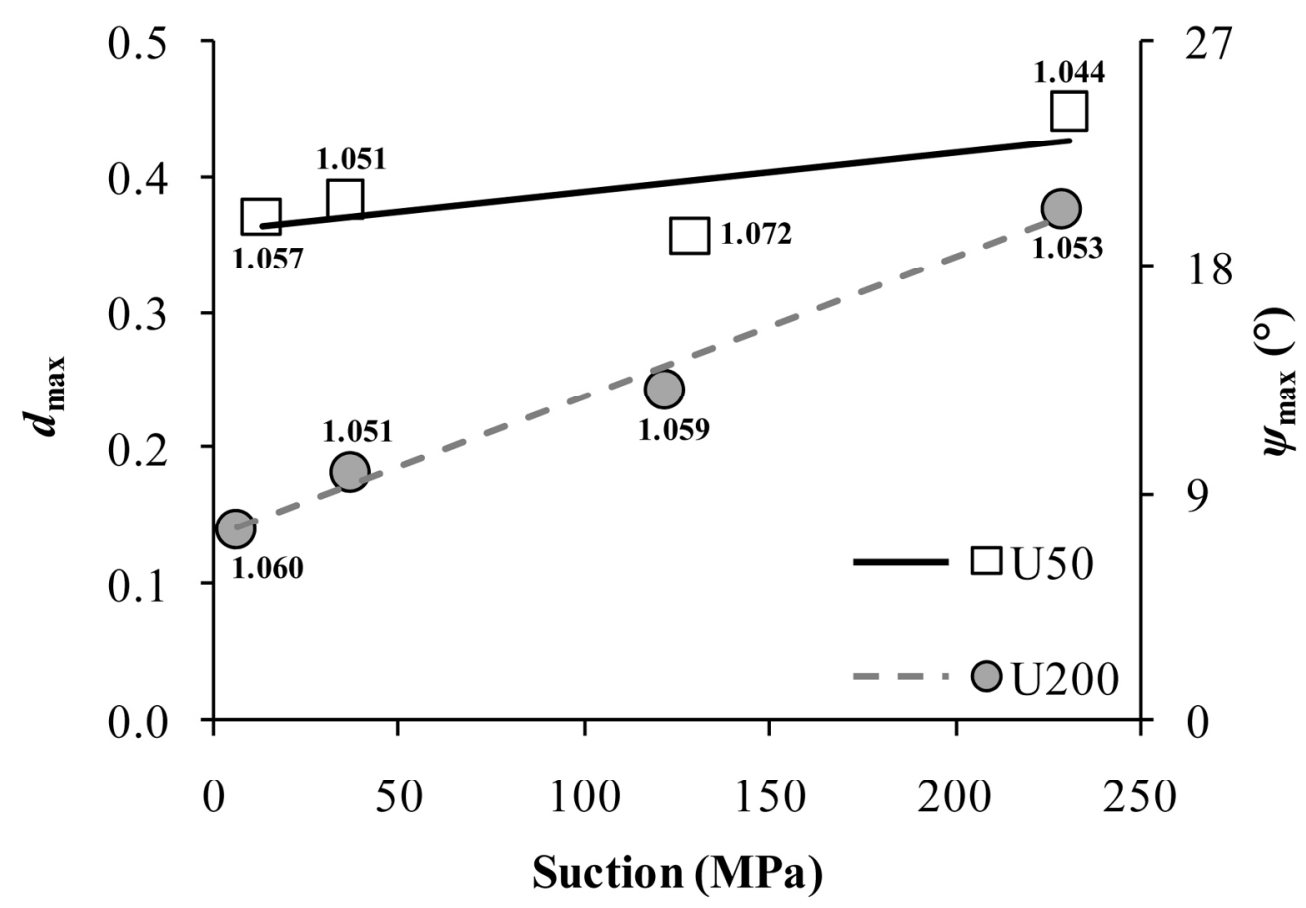

Fig. 11. The influence of suction on maximum dilatancy of recompacted loess.

$157 \times 107 \mathrm{~mm}(300 \times 300$ DPI $)$ 